\title{
The Holistic Leadership Model and the Nurse Unit Manager: Assessing Requisite Leadership Competencies in the Rwandan Context
}

\author{
Aphrodis Gustave Tuyishime ${ }^{1}$ and William Rosa ${ }^{2 *}$ \\ ${ }^{1}$ Neonatal intensive care unit at Rwanda Military Hospital. \\ ${ }^{2}$ University of Rwanda and ICU Clinical Educator, Rwanda Military Hospital, Human Resources for Health Program in \\ partnership with the New York University Rory Meyers College of Nursing.
}

\begin{abstract}
Effective leadership is arguably one of the most relevant indicators of a profession's advancement or lack thereof. The purpose of this article is to share the authors' personal views on the leadership competencies necessary for the nurse unit manager transitioning into the role for the first time. To identify these leadership requisites, the literature was searched to identify key competencies and characteristics of effective nurse leaders across disciplines and specialties, both globally and unique to the African and Rwandan contexts. In the ever-changing healthcare scenario in Rwanda, the efforts and accomplishments of the Human Resources for Health (HRH) Program are described as just one catalyst for the increased numbers of new nurse unit managers. Through analysis of the literature in conjunction with personal experience, the authors recommend the Holistic Leadership Model rooted in an ethic of caring as a tool for new nurse unit managers to become effective leaders and agents of meaningful change.
\end{abstract}

Keywords: Nurse; nursing practice; leadership; management; caring; competencies; holistic nursing

\section{Introduction}

Effective leadership is arguably one of the most relevant indicators of a profession's advancement or lack thereof. Ekström \& Idvall (2015) suggest that nurses transitioning into a first-time leadership role may find difficulty in developing a unique leadership style that achieves institutional goals while promoting unit teamwork, collaboration, and successful interdisciplinary communication. In Africa, it has been noted that the nurse unit manager is the leader most responsible for assisting nurses in developing a professional identity through the manager's own attention to self-awareness, self-motivation, and self-confidence (Jooste \& Cairns, 2014). The purpose of this article is to share the authors' personal views on the leadership competencies necessary for the nurse unit manager transitioning into the role for the first time in a Rwandan tertiary care hospital. Through a brief review of the literature on leadership in nursing and, more specifically, nursing leadership in Africa, the authors propose an innovative model of success for new nurse unit managers based on existing leadership models and theories. The recommended model of leadership provides the new nurse unit manager with a holistic approach to leadership that has the potential to create a work environment defined by innovation, collaboration, resilience, and transformation.

\section{Background \& Significance}

\section{The Human Resources for Health Program}

In August 2012, Rwanda's Ministry of Health (MOH) partnered with a consortium of academic medical institutions, as well as nursing, public health, and dentistry schools, to create the Human Resources for Health $(\mathrm{HRH})$ Program. The HRH program is a 7-year initiative, currently in year 4, explicitly concerned with skills and knowledge transfer between Rwandan colleagues and United States Institution (USI) faculty. Such skills transfer occurs through Rwandan-US partnership and collaboration to improve both the status of healthcare quality, and the educational preparation for nurses, physicians, healthcare administrators, and dental health workers (Binagwaho et al., 2013). The overarching goal of the HRH Program is to place the Rwandan healthcare workforce in the position to promote and maintain autonomous and empowered practice that increases the access to and delivery of care while decreasing dependence on foreign aid (Republic of Rwanda, Ministry of Health, n.d.).

The HRH Program has created several opportunities in nursing preparation, practice, and planning across Rwanda. Some of these initiatives include the introduction of a blended learning model that combines classroom learning with online learning (Mulaudzi \& Chyun, 2015); tracking the success of nursing and midwifery outcomes in accordance with the $2009 \mathrm{MOH}$ guidelines (Gitembagara, Relf, \& Pyburn, 2015); and furthering the understanding of what it means to be true collaborators in the future of a global healthcare infrastructure (Hardtman, Dufatanye, \& Maribori, 2015). Rwandan colleagues and US faculty are partnering to create an environment of teaching-learning that links the classroom to practice, theory to action; facilitating new possibilities in Rwandan healthcare praxis.

Additionally, the HRH Program has spearheaded countless advancements for nursing professional development and continuing post-baccalaureate education. For example, as of fall 2015, the School of Nursing and Midwifery at the University of Rwanda started the country's first-ever Masters of Science in Nursing (MScN) program, admitting well over 100 students into its inaugural cohort. This MScN program has attracted capable nurses with at least two years of field experience from all Rwandan provinces, particularly those clinicians with leadership background. 
With the advent of these changes, there will continue to be substantial opportunities for clinical staff nurses to assume nurse unit manager roles and various other positions of authority. As more nurses move into these posts, a reliable and detailed leadership framework is necessary so they may successfully fulfill their heightened responsibilities. In the following sections, this article will explore the competencies deemed necessary for effective leadership, current descriptions of and gaps in nursing leadership in Africa and Rwanda, and suggestions for how these new nurse unit managers can develop themselves to lead with confidence and success.

\section{Leadership Competencies in Nursing}

\section{A Global Perspective}

In compiling the requisites of leadership for the nurse unit manager, the literature was searched to identify key competencies and characteristics of effective leaders across disciplines and specialties. Patterson and Krouse (2015) identifyfour primary skills for the leader in nursing education, generalized and adapted below for the purpose of this article. The nurse manager should be able to:

- Articulate and promote a vision

- Function as a steward for the organization

- Embrace professional value in context

- Develop and nurture relationships.

Being able to demonstrate these competencies may assist the nurse leader during their transition into a new role by clarifying their purpose and promoting teamwork collaboration. On a global scale, nurse leaders may apply these competencies to create and advance health policy and the public perception of nursing, foster workforce development, care delivery, professional status, and advocate for governmental/system support (Wong et al., 2015). Powerful leadership skills are required to increase the influence of nursing in these areas and continue to improve patient outcomes.

In the authors' opinion, one of the primary questions asked by the staff nurse preparing to assume nurse unit manager responsibilities is, "Will I become a manager or a leader?" Taffinder (2006) identifies the main differences between the two: a manager tends to control risks, enforce organizational rules, and seek and follow direction, whereas a leader seeks opportunities, changes organizational rules that no longer work, and provides something for others to believe in. According to Taffinder (2015), additional characteristics of a leader include the abilities to set the context and make it clear what priorities matter, be unpredictable, commit to a deep conviction, and make things happen at mass scale. Nurse unit managers who understand the difference between these two previously mentioned roles have the option of practicing behaviors that can change their leadership trajectory.

\section{The African Context}

The literature pertaining to nursing leadership in the African context not only clearly identifies which leadership styles are ineffective, but also calls for increased training, skills development, and a broader understanding of the leadership role. Throughout sub-Saharan Africa, it has been noted that many nurses promoted to significant leadership roles lack the necessary leadership experience or critical thinking educationrequiredfor success (Nakanjako et al., 2015). In South Africa, Pillay (2011) noted that many nurse managers in the public health sector believe being able to control staff is the most critical competency, followed by leading, organizing, and self-management. Considered even less relevant to the role of nurse manager were clinical skills, planning, and the development of legal/ethical competencies (Pillay, 2011). Maboko (2011) made it clear that these autocratic leadership styles simply do not work and nurse managers need to learn more about contemporary models of leadership, and hone the abilities to supervise, role model, and demonstrate caring. These contemporary leadership models, such as transformational leadership, help increase motivation for all workers and improve collaborative partnerships. A lack of transformational leadership in the African context may be responsible for the high turnover of staff in hospitals, which worsens the burden of staff shortage, and increases the difficulty of retaining well-trained nurses (Botma, Botha \& Nel, 2011).

In East Africa, it was observed that there were specific leadership attributes required to promote population health, implement change strategies, and advance nursing professional development (Shariff, 2015). These characteristics included being able to:

- Influence

- Communicate effectively

- Build relationships

- Feel empowered

- Demonstrate professional credibility.

In a milieu of scarce or limited resources, these skills must be practiced through a lens of strategic thinking, teaching, and learning in order to maintain ongoing success (Jumaa \& Rendel, 2007). In fact, a more holistic style of leadership is called for so that strategic action plans can be employed along with attention to emotional, social, and spiritual competencies (Jumaa \& Rendel, 2007).

More specific to Rwanda, the importance of innovation in nursing leadership cannot be overlooked. In resourceconstrained settings, nurses need to be able to creatively "do more with less;" to improve clinical outcomes by transforming outdated nursing practices and develop new approaches to care (Brysiewicz, Hughes \& McCreary, 2015). If nurse leaders are able to procure environments that nurture innovation, vulnerability, and creativity, staff will respond by taking risks, expressing talents, and sharing ideas (Brown, 2012), which may significantly and positively impact patient care. It is ultimately the nurse unit manager's responsibility to promote environments of innovation that make it safe for staff to participate in the processes of meaningful change (Brysiewicz et al., 2015).

As East African Countries look to collaborate and potentially unify nursing and midwifery education, practice, and legislation across nations, it is vital that nurses understand the impact of their leadership and mentorship in improving quality care throughout Rwanda (Leshabari, 
Nabirye, Mukamana, \& Mill, 2015; Anatole et al., 2012). Based on the literature mentioned above, the nurse manager must take accountability for creating transformational environments of leadership that promote relationship-building, caring, innovation, and a holistic approach to patient care. It is from this needs assessment of nurse leadership in the African context that these authors adopted an emerging model of leadership to aid new nurse managers in assuming their role with confidence.

\section{The Holistic Leadership Model}

As a new nurse unit manager, the author searched for a model of leadership that would assist him in successfully fulfilling the responsibilities of his new role, build meaningful relationships, and create a caring environment for staff and patients. The Holistic Leadership Model (HLM) is informed by the concepts and frameworks of transformational leadership, influential leadership, and servant leadership, and also emphasizes nursing professional practice models rooted in caring and healing theories (Andrus \& Shanahan, 2016). According to the HLM, there are seven core characteristics of a holistic leader, listed and briefly described in Table 1. Each of these characteristics is central to the work of a fully functioning nurse unit manager and can be viewed as parts of the leadership role, as illustrated in Figure 1. This author proposes that by adopting the HLM and striving toward true demonstrations of these characteristics in practice, the new nurse unit manager can become

efficient and influential among his colleagues and with patients.

Table 1. Seven Core Characteristics of a Holistic Leader (Andrus \& Shanahan, 2016) With Brief Descriptions

\begin{tabular}{|c|c|}
\hline Core Characteristics & Brief Descriptions \\
\hline 1. Visionary & $\begin{array}{l}\text { - Open to learning from others' points of view through deep listening and } \\
\text { nonjudgmental attitude } \\
\text { - } \quad \text { Understands the deeper spiritual needs of staff and the organization } \\
-\quad \text { Sees big picture and utilizes out-of-the-box thinking } \\
\text { - Promotes innovation and collaboration }\end{array}$ \\
\hline 2. Inspirational presence & $\begin{array}{l}\text { - } \quad \text { Inspires others through inclusion, respect, caring, and acknowledgment } \\
\text { - } \quad \text { Cultivates commitment and passion } \\
\text { - } \quad \text { Commits to genuine and authentic words and actions }\end{array}$ \\
\hline 3. Role model & $\begin{array}{l}\text { - Sets standards of excellence and serves as a positive example for others } \\
\text { Embraces four principles: maintains integrity, upholds ethical } \\
\text { standards, demonstrates bold and courageous actions, and remains } \\
\text { visible-approachable-accessible }\end{array}$ \\
\hline 4. Mentor & $\begin{array}{l}\text { - Promotes shared teaching-learning for an environment of mutual } \\
\text { growth } \\
\text { - } \quad \text { Nemonstrates commitment to lifelong learning } \\
\quad\end{array}$ \\
\hline 5. Champion for clinical excellence & $\begin{array}{l}\text { - Links art of caring to nurse-patient outcomes } \\
\text { - } \quad \text { Encourages education and learning at every level } \\
\text { - Holds nurses accountable for clinical excellence }\end{array}$ \\
\hline 6. Courageous advocate & $\begin{array}{l}\text { Exhibits unwavering commitment to achieving the best for staff, } \\
\text { patients, the community, and the environment }\end{array}$ \\
\hline 7. Cultural transformational agent & $\begin{array}{l}\text { - Holds the vision for and works to realize a transformed culture of } \\
\text { caring-healing for all }\end{array}$ \\
\hline
\end{tabular}

Figure 1. Nurse Unit Manager as Holistic Nurse Leader Role: Component Parts

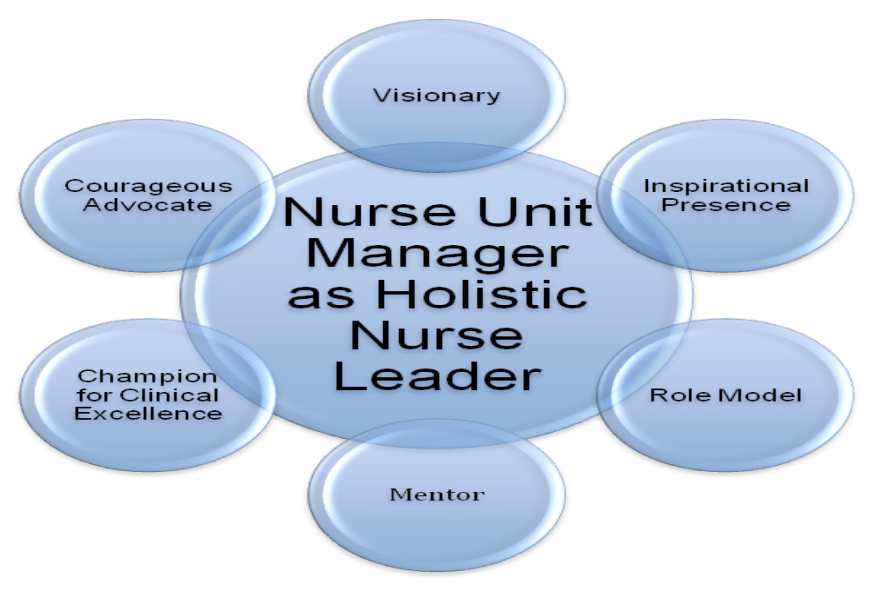




\section{The Nurse Unit Manager as Change Agent}

Change is an integral part of the current health care scenario worldwide, and particularly in Rwanda, as advances in education and research are implemented, and the scope of practice expands to meet the ongoing development of health care service delivery. Understanding the role of the nurse unit manager as a change agent is vital to effective leadership. Sullivan (2012) defines a change as "the process of making something different from what it was" and describes the change agent as "one who works to bring about a change" (p. 56). The HLM equips the nurse unit manager as change agent with the values and ethics required to powerfully handle the conflict that inevitably occurs as a result of change. As a change agent, the nurse unit manager can learn to aid staff in surrendering old practice methods, questioning the status quo, and coach them through the challenges of the change process by remaining enthusiastic and positive (Grossman \& Valiga, 2013).

\section{A Word on Caring}

Several extant nursing theories describe caring as the foundational ethic and moral imperative of nursing practice (Boykin \& Schoenhofer, 2001; Leininger, 1976; Roach, 2002; Watson, 2008, 2012). Without an intention or lived demonstration of caring, the nurse unit manager may be challenged to embody the core characteristics of the HLM or be an effective agent for meaningful change. As the nurse unit manager comes to appreciate the wholeness and uniqueness of staff and colleagues through caring relationship building, the potential for a healing environment for all individuals and the organization at large becomes possible (Quinn, 2016). The holistic caring process for the nurse unit manager suggests the ability to integrate evidence-based practice with self-reflection and self-growth to create healthy work environments (Potter \& Frisch, 2016).

\section{Conclusion}

The transition of the staff nurse into the nurse unit manager role can be overwhelming for even the most expert of clinicians. As they strive to meet administrative expectations and collaborate with colleagues to realize institutional goals, the nurse unit manager needs reliable and detailed frameworks to assist them in successfully fulfilling their new responsibilities. It is essential to have an understanding of how leadership is cultivated in the relevant context before adopting a particular lens. Additional research specific to nursing hierarchy expectations in the Rwandan context would be helpful for directing leadership development in the future. For the Rwandan nurse unit manager learning to implement effective leadership, these authors recommend the HLM rooted in an ethic of caring to guide positive outcomes and meaningful change.

\section{References}

Anatole, M., Magge, H., Redditt, V., Karamaga, A., Niyonzima, S., Drobac, P., Hirschhorn, L.R. (2012). Nurse mentorship to improve the quality of health care delivery in rural Rwanda.Nursing Outlook, 61, 137144.

Andrus, V.L. \& Shanahan, M.M. (2016). Holistic leadership. In B.M. Dossey\& L. Keegan (Eds.), Holistic nursing: $A$ handbook for practice ( $7^{\text {th }}$ ed., pp. 591-607). Burlington, MA: Jones \& Bartlett Learning.

Binagwaho, A., Kyamanywa, P., Farmer, P.E., Nuthulaganti, T., Umubyeyi, B., Nyemazi, J.P., Goosby, E. (2013). Human Resources for Health Program in Rwanda: A new partnership. New England Journal of Medicine, 369(21), 20542059.

Botma, Y. Botha, H., \&Nel, M. (2011). Transformation: are nurse leaders in critical care ready? Journal of Nursing Management, 20, 921-927.

Boykin, A. \&Schoenhofer, S.O. (2001). Nursing as caring: A model for transforming practice. Sudbury, MA: Jones and Bartlett Publishers.

Brown, B. (2012). Daring greatly: How the courage to be vulnerable transforms the way we live, love, parent, and lead. New York: Gotham.

Brysiewicz, P., Hughes, T.L., \& McCreary, L.L. (2015). Promoting innovation in global nursing practice. Rwanda Journal Series F: Medicine and Health Sciences, 2(2), 41-45.

Ekström, L. \&Idvall, E. (2015). Being a team leader: newly registered nurses relate their experiences. Journal of Nursing Management, 23, 75-86.

Gitembagara, A., Relf, M.V., \&Pyburn, R. (2015). Optimizing nursing and midwifery practice in Rwanda. Rwanda Journal Series F: Medicine and Health Sciences, 2(2), 26-30.

Grossman, S.C. \&Valiga, T.M. (2013). The new leadership challenge: Creating the future of nursing $\left(4^{\text {th }}\right.$ ed.). Philadelphia, PA: F.A. Davis.

Hardtman, P., Dufatanye, E., \&Maribori, C. (2015). Global collaboration in nursing and midwifery "talking it out". Rwanda Journal Series F: Medicine and Health Sciences, 2(2), 36-40.

Jooste, K. \& Cairns, L. (2014). Comparing nurse managers and nurses' perceptions of nurses' selfleadership during capacity building. Journal of Nursing Management, 22, 532-539.

Jumaa, M.O. \&Rendal, H.P.L. (2007). Effective evidence based nursing leadership and efficient nursing management: Work based learning lessons from a Catholic health service in Africa. West African Journal of Nursing, 18(2), 114-125.

Leshabari, S., Nabirye, R.C., Mukamana, D.\& Mill, J. (2015). Looking forward to the East African Countries' collaboration in nursing and midwifery education, practice and legislation. Rwanda Journal Series F: Medicine and Health Sciences, 2(2), 69-73. 
Maboko, D.R. (2011). Nursing leadership in an academic hospital in Gauteng. Journal of Nursing Management, 20, 912-920.

Mulaudzi, F.M. \&Chyun, D.A. (2015). Innovation in nursing and midwifery education and research. Rwanda Journal Series F: Medicine and Health Sciences, 2(2), 21- 25.

Nakanjako, D., Namagala, E., Semeere, A., Kigozi, J., Selmpa, J., Ddamulira, J.B., . . .

Sewankambo, N. (2015). Global health leadership training in resource-limited settings: a collaborative approach by academic institutions and local health care programs in Uganda. Human Resources for Health, 13, 1-9 9p.

Patterson, B.J. \&Krouse, A.M. (2015). Competencies for leaders in nursing education. Nursing Education Perspectives, 36(2), 76-82.

Pillay, R. (2011). The skills gap in nursing management in the South African public health sector. Public Health Nursing, 28(2), 176-185.

Potter, P.J. \& Frisch, N.C. (2016). The holistic caring process.In B.M. Dossey\& L. Keegan (Eds.), Holistic nursing: A handbook for practice ( $7^{\text {th }}$ ed., pp. 167-186). Burlington, MA: Jones \& Bartlett Learning.

Quinn, J. (2016). Transpersonal human caring and healing. In B.M. Dossey\& L. Keegan (Eds.), Holistic nursing: $A$ handbook for practice $\left(7^{\text {th }}\right.$ ed., pp. 101-110). Burlington, MA: Jones \& Bartlett Learning.

Republic of Rwanda, Ministry of Health. (n.d.). Human Resources for Health Program, Republic of Rwanda: Program overview. Retrieved from http://www. hrhconsortium.moh.gov.rw/about-hrh/programoverview/

Roach, M.S. (2002). Caring, the human mode of being: A blueprint for the health professions ( $2^{\text {nd }} \operatorname{Rev}$. ed.). Ottawa, Canada: CHA Press.

Sharif, N.J. (2015). A Delphi survery of leadership attributes necessary for national nurse leaders' participation in health policy development: an East African perspective. BMC Nursing, 14(1), 1-8 $8 p$.

Sullivan, E.J. (2012). Effective leadership and management in nursing $\left(8^{\text {th }}\right.$ ed.). Upper Saddle River, $\mathrm{NJ}$ : Pearson.

Taffinder, P. (2006). The leadership crash course: How to create personal leadership value ( $2^{\text {nd }}$ ed. $)$. Philadelphia, PA: Kogan Page.

Watson, J. (2008). Nursing: The philosophy and science of caring (Rev. ed.). Boulder, CO: University Press of Colorado.

Watson, J. (2012). Human caring science: $A$ theory of nursing(2nd ed.). Sudbury, MA: Jones \& Bartlett Learning.

Wong, F.K.Y., Liu, H., Wang, H., Anderson, D., Seib, C.\&Molasiotis, A. (2015). Global nursing issues and development: Analysis of World Health Organization documents. Journal of Nursing Scholarship, 47(6), 574-583. 